\title{
Knowledge, Attitudes and Practice about Pap Smear Test among Women Living in Bojnourd, North East of Iran: a Population-Based Study
}

\author{
Narjes Bahri ${ }^{1}$, Roya Jajvandian ${ }^{2}$,Maryam Bolandhemmat ${ }^{3 *}$, Khadigeh Mirzaii \\ Najmabadi $^{4}$
}

\begin{abstract}
Background: The aim of the study was to assess the extent of knowledge, attitudes and practical behavior of women in Bojnourd conerning the Pap smear test. Materials and Methods: This cross-sectional and populationbased study was conducted with 1000 Iranian women aged 15-60 years old in Bojnourd city. In order to collect the data, a validated questionnaire was provided in four sections covering demographic information and questions about knowledge, attitude and practice about the Pap smear. Statistical analysis was performed with the Statistical Package for Social Sciences (version 17.0) applying a 0.05 significance level. Results: Evaluation of knowledge showed that 146 women $(14.6 \%)$ had very weak, and 594 women $(59.4 \%)$ had weak knowledge. In contrast, most of the women studied, $873(87.3 \%)$, had a positive attitude toward the Pap smear test. According to the findings, 375 women $(37.6 \%)$ had done this test so far. Findings indicated that the extent of knowledge had a meaningful relationship with the attitude status $(\mathbf{p}<\mathbf{0 . 0 0 0 1})$. Also, there was a meaningful relationship between knowledge and practice, so that the weakest practice was seen in women who had weak knowledge $(61.1 \%),(p<0.0001)$. Conclusions: According to findings of this research, most women do not have an appropriate knowledge about the necessity of having the Pap smear test, so that only a low percentage of women had undergone this test.
\end{abstract}

Keywords: Pap smear test - cervical cancer - knowledge - attitude - practice - North-east Iran

Asian Pac J Cancer Prev, 16 (5), 2013-2018

\section{Introduction}

Nowadays, cancer is an enormous global health burden, in every region and socioeconomic level. Cervical cancer is one of the most common cancers in women and it is the fourth most common cancer-related deaths in women (Onsuz et al., 2014). Although cervical cancer is preventable, annually about half a million women that have cervical cancer are detected all over the world which accounts for 270,000 deaths and makes the second leading cause of cancer in women (Monsonego et al., 2007; WHO, 2013; Anaya-Ruiz et al., 2014).

Internationally, cervical cancer is the second common cancer among women (Akujobi et al., 2008), also it is a major cause of cancer mortality in low-income countries (Ilter et al., 2010; Wright et al., 2010) and 85\% of these mortalities occur in developing countries (Serrano et al., 2014). According to these reasons, cervical cancer remains as a serious health problem in the world. In developing countries, which do not have screening programs, cervical cancer is one of the obvious causes of mortality (Othman et al., 2014). However, this cancer is known as a preventable cancer because it has one long pre-invasion step and available cytology screening programs (Monsonego et al., 2007). From this aspect, identification of risk factors and screening are always considerable health policies in the society (Amarian et al., 2008). The Pap smear test is the most suitable test for screening of cervical neoplasia (Gakidou et al., 2008). In the 1960s and 1970s, incidence rates in the developed countries were similar to those seen in the developing countries today; the subsequent decline in cervical cancer incidence and mortality in high-income countries is largely attributed to effective screening programs (Khan et al., 2014). This test was introduced by Papanicolau for the first time in order to determine reproduction cycle of animals (Gakidou et al., 2008). The test needs high acceptance by women, high quality in performance and pursuing of abnormal cases. However, in some developing countries, women have very limited knowledge about this cancer (Anaya-Ruiz et al., 2014;

${ }^{1}$ Department of Midwifery, School of Nursing and Midwifery, Gonabad University of Medical Sciences, Gonabad, ${ }^{2,3}$ Department of Midwifery, Islamic Azad University, Bojnourd Branch, Bojnourd, ${ }^{4}$ Department of Midwifery, School of Nursing and Midwifery, Mashhad University of Medical Sciences, Mashhad,Iran.*For correspondence: mbolandhemmat@gmail.com 
Onsuz et al., 2014; Ranabhat et al., 2014). The difference in the mortality of cervical cancer between developed and developing countries is directly related to performing or not performing Pap smear tests (Wright et al., 2010). Healthy behavior cognition of these beliefs and evaluation of knowledge about the Pap smear test are necessary in planning of programs in order to improve this activity.

Akujobi and his colleagues, while researching in east north of Nigeria on 220 psychology students, found that the knowledge level of students about cervical cancer is high, but their participation in cervical screening is low (Akujobi et al., 2008). Results of research of Gichangi and colleagues show that the extent of knowledge about Pap smear screening among people who have cervical cancer and healthy people are low in the Kenai (Gichangi et al., 2003). Tung and colleagues assessed 222 Taiwanese women and understood barriers related to worry; embarrassment, stigma, and lack of female physicians as significant factors in the active participation in the screening test (Tung et al., 2010).

Generally, demographic factors and social factors like social class, lack of health insurance, financial parameters and also cultural factors such as beliefs; attitudes and awareness about disease of cervix and screening are important factors of a person's participation in cancer screening (Amarian et al., 2008; Ranabhat et al., 2014). Considering the importance of knowledge, attitude and action of women about the Pap smear, the extent of knowledge, attitude and practice of women in north khorasan-Bojnourd about this test has been studied. Obtained results of this research can provide a compass for applicable studies and instructional plans for screening of cervical cancer.

\section{Materials and Methods}

\section{Study design and setting}

This cross-sectional, population-based study was conducted to investigate the state of knowledge, attitudes, and practices of women aged 15-60 years old toward Pap smears, in Bojnourd located in the north east of Iran. The research protocol was approved by the ethics committee of Islamic Azad University; Bojnourd branch and all participants gave written informed consent.

\section{Participants}

Participants were 1000 married women aged between 15 and 60 years in Bojnourd. The method of sampling was determined orderly from every zone of municipality of Bojnourd on the basis of demographic and settlement information. Participants were selected on the basis of simple random sampling without replacement.

\section{Measures and data collection}

This questionnaire contained mostly pre-coded questions, with some open ones. We used and adapted questions taken from questionnaires used in other studies (Gamarra et al.,2005; Amarian et al., 2008). The following instruments were applied:

i) Socio demographic questionnaire: The socio demographic questionnaire contained questions regarding demographic information including: age, marital status, educational level of the woman and her husband, occupation, number of parturition, family history of cancer, and training history about Pap smears.

ii) Knowledge questionnaire: This questionnaire contained a series of questions to assess knowledge about the Pap smear test. Obtained knowledge scores were classified in five groups, including very weak (0-4 scores), weak (5-8 scores), medium (9-12 scores), good

Table 1. Demographic Characteristics of the Study Population (N=1000)

\begin{tabular}{|c|c|c|}
\hline Participant demographics & Number & Percentage \\
\hline \multicolumn{3}{|l|}{ Age } \\
\hline $13-18$ & 28 & 2.8 \\
\hline $19-23$ & 139 & 13.9 \\
\hline $24-29$ & 298 & 29.8 \\
\hline $30-35$ & 201 & 20.1 \\
\hline $36-41$ & 153 & 15.3 \\
\hline $42-47$ & 93 & 9.3 \\
\hline$>48$ & 88 & 8.8 \\
\hline Mean \pm S.D. & $19.1 \pm 3.6$ & \\
\hline \multicolumn{3}{|l|}{ Marital Status } \\
\hline Married & 968 & 96.8 \\
\hline Divorced or widow & 32 & 3.2 \\
\hline \multicolumn{3}{|l|}{ Education Level } \\
\hline Illiterate & 53 & 5.3 \\
\hline Primary school & 148 & 14.8 \\
\hline Secondary school & 196 & 19.6 \\
\hline High school & 364 & 36.4 \\
\hline Higher education & 237 & 23.7 \\
\hline \multicolumn{3}{|l|}{ Employment Status } \\
\hline Housewife & 720 & 72 \\
\hline Employed & 280 & 28 \\
\hline \multicolumn{3}{|l|}{ Gravidity } \\
\hline $0-1$ & 276 & 27.6 \\
\hline $2-3$ & 568 & 56.8 \\
\hline$<4$ & 156 & 15.6 \\
\hline \multicolumn{3}{|l|}{ Type of contraception } \\
\hline Hormonal & 291 & 31 \\
\hline IUD & 99 & 10.5 \\
\hline Condon & 176 & 18.7 \\
\hline Withdrawal method & 374 & 39.8 \\
\hline
\end{tabular}

Table 2. Knowledge, Source of Knowledge, Attitude and Practice about the Pap Smear Test $(\mathrm{N}=1000)$

\begin{tabular}{lcc}
\hline KAP & Number & Percent \\
\hline Knowledge & & \\
Extremely weak & 146 & 14.6 \\
Weak & 594 & 59.4 \\
Mediocre & 134 & 13.4 \\
Good & 79 & 7.9 \\
Excellent & 47 & 4.7 \\
Attitude & & \\
Positive & 873 & 87.3 \\
Unbiased & 102 & 10.2 \\
Negative & 25 & 2.5 \\
Practice & & \\
Weak & 621 & 62.1 \\
Mediocre & 289 & 28.9 \\
Good & 90 & 9 \\
\hline
\end{tabular}


Knowledge, Attitude and Practice about Pap Smear Test among Women Living in Bojnourd, North East of Iran (13-16 scores) and excellent (17-20 scores). Also we considered good and perfect knowledge as constituting the knowledge group.

iii) Attitudes questionnaire: This questionnaire contained a set of phrases to evaluate attitude towards the Pap smear as an uncomfortable experience. Evaluation of the women's attitude was estimated by a three-point Likert scale (positive, negative, and indifferent). Positive attitude was considered as satisfactory.

iiv) Practice questionnaire: This questionnaire contained a series of questions about practice of the Pap smear. Obtained practice scores were classified in three groups: good (had done once in a year), mediocre (had done once in 2 or 3 years) and weak practice (has not done this test more than three years prior or never had the test). Women who had a Pap smear test during the past three years were considered as having enough practice.

The questionnaire was tested for content validity by the process of widespread discussion and advice with experts in the respective field as well as published literatures and referral texts. Also the questionnaire was pretested through a pilot study on 30 women who were excluded from survey. Suitable modifications like changing words in some questions were made. The reliability of each questionnaire was calculated by using the method of alpha-Chronbach. It was calculated 0.78 for the knowledge questionnaire, 0.77 for the attitude questionnaire and 0.76 for the practice questionnaire.

Data collection was done by six midwives. They went to the selected participants' homes, demonstrated formal presentations from university, and explained about the objectives of the research. If the participants signed the informed consent, the midwives asked them to fill out the questionnaires at that moment.

\section{Statistical analysis}

Statistical evaluation was done using the Statistical Package for Social Sciences (version 17.0). Descriptive statistics were used to calculate frequencies of responses for all demographic, knowledge, attitude, and practice items. Chi-squared analysis was employed to test associations among knowledge, attitudes, and practices.

Also, ANOVA and chi-square were used to determine differences between knowledge, attitude and practice regarding the Pap smear according to participant's characteristics. We considered $P$ value $<0.05$ as statistically significant

\section{Results}

Participant Characteristics: In this study 1000 women had filled out the questionnaires completely. Demographics of the participants about age, marital status, education, gravidity and type of contraception are shown in Table 1.

A large percentage of women $(627,62.4 \%)$ had not learned about the Pap smear test. Also the most commonly used sources of information were physician and health practitioners $(47.3 \%)$.

Knowledge related to Pap smears: Evaluation of women's knowledge showed that a large percentage of participants $(594,59.4 \%)$ had weak knowledge; in contrast, only 7.9 percent (79 persons) of women had good knowledge (Table 2).

Attitudes related to Pap smears: The results showed that most of participants $(87.3 \%)$ had a positive attitude about the Pap smear test, whereas, women with a negative attitude accounted for only 25 persons $(2.5 \%)$ (see Table 2).

Practices related to Pap smears: According to the findings, 375 women (37.6\%) had done the Pap smear test until three years ago; on the contrary, the majority, with a total samples (62.4\%) had not done this test yet (Table 2).

Findings about the relations between knowledge, attitude and practice showed that knowledge had statistically significant relationship with attitude ( $p<0.0001)$, so that those with median knowledge level had the most positive attitude. Additionally, knowledge was associated with practice, meaning that participants with weak knowledge had weak practice $(\mathrm{p}<0.0001)$. However, there was no significant relationship observed between attitude and practice $(\mathrm{p}=0.616)$. (Table 3$)$.

Findings about the relation of enough knowledge, attitude and practice with participant's characteristics showed that, significantly greater proportions of enough attitudes were identified among women who reported use of hormonal contraceptive method.

In addition, the majority of women with enough practice had the benefit of secondary education (their spouse also had secondary education), reported use of withdrawal method as a contraceptive method, had 2-3 children, were housekeepers, and their age was 24-29 years.

Table 3. Observing Relations among Knowledge, Attitude and Practice ( $N=1000)$

\begin{tabular}{|c|c|c|c|c|c|c|c|c|c|}
\hline \multirow{2}{*}{ Knowledge } & \multicolumn{3}{|c|}{ Attitude } & \multicolumn{6}{|c|}{ Practice } \\
\hline & Positive & Unbiased & Negative & & Weak & & Mediocre & & Good \\
\hline Very weak & $112(76.7)$ & $29(19.9 \%)$ & $5(3.4 \%)$ & 98 & $(15.6 \%)$ & 39 & $(13.5 \%)$ & 9 & $(10 \%)$ \\
\hline Weak & $540(90.9)$ & $47(7.9 \%)$ & $7 \quad(1.2 \%)$ & 379 & $(61.1 \%)$ & 60 & $(9.7 \%)$ & 51 & $(8.2 \%)$ \\
\hline Mediocre & $121(90.3 \%$ & $12(9 \%)$ & $1 \quad(0.7 \%)$ & 164 & $(56.7 \%)$ & 50 & $(17.3 \%)$ & 24 & $(8.3 \%)$ \\
\hline Good & $60(75.9 \%)$ & $11(13.9 \%)$ & $8(10.1 \%)$ & 51 & $(56.7 \%)$ & 24 & $(26.7 \%)$ & 4 & $(4.4 \%)$ \\
\hline Excellent & $40(85.1 \%)$ & $3(6.4 \%)$ & $4 \quad(8.5 \%)$ & 33 & $(5.3 \%)$ & 12 & $(4.2 \%)$ & 2 & $(2.2 \%)$ \\
\hline \multirow[t]{2}{*}{ Total } & $873(87.3)$ & $102(10.2 \%)$ & $25(2.5 \%)$ & \multicolumn{2}{|c|}{$621(100 \%)$} & 289 & $100 \%)$ & \multicolumn{2}{|c|}{$90(100 \%)$} \\
\hline & \multicolumn{3}{|c|}{ P-value $<0.000$} & \multicolumn{6}{|c|}{$\mathrm{P}$-value $<0.001$} \\
\hline
\end{tabular}


Table 4. Evaluation of Enough Knowledge, Attitude and Practice Concerning the Pap smear test According to the Characteristics Studied (N=1000)

\begin{tabular}{|c|c|c|c|}
\hline $\begin{array}{l}\text { Participant demographics } \\
\text { Number }(\%)\end{array}$ & $\begin{array}{c}\text { Enough Knowledge } \\
\text { Number }(\%)\end{array}$ & $\begin{array}{l}\text { Enough Attitude } \\
\text { Number }(\%)\end{array}$ & Enough Practice \\
\hline \multicolumn{4}{|l|}{ Age } \\
\hline $13-18$ & $6(5.3)$ & $5(6.5)$ & $7(1.9)$ \\
\hline $19-23$ & $23(20.4)$ & $13(16.9)$ & $30(8.1)$ \\
\hline $24-29$ & $31(27.4)$ & $26(33.8)$ & $150(28.2)$ \\
\hline $30-35$ & $17(5)$ & 13(16.9) & $86(23.1)$ \\
\hline $36-41$ & $16(14.2)$ & 13(16.9) & $72(19.4)$ \\
\hline $42-47$ & $14(12.4)$ & $40(5.2)$ & $37(9.9)$ \\
\hline$>48$ & $61(5.3)$ & $3(3.9)$ & $35(9.4)$ \\
\hline $\mathrm{P}$ - value & 0.25 & 0.428 & $<0.000$ \\
\hline \multicolumn{4}{|l|}{ Marital Status } \\
\hline Married & $106(93.8)^{\prime}$ & $75(97.4)$ & $365(98.1)$ \\
\hline Divorced or widow & $7(6.2)$ & $2(2.6)$ & $7(1.9)$ \\
\hline $\mathrm{P}$ value & 0.244 & 0.385 & 0.204 \\
\hline \multicolumn{4}{|l|}{ Education Levels } \\
\hline Illiterate & $12(10.7)$ & $1(1.3)$ & $11(0.03)$ \\
\hline Primary school & $23(20.5)$ & $18(23.4)$ & $43(11.6)$ \\
\hline Secondary school & $18(16.1)$ & $20(26)$ & $68(18.3)$ \\
\hline High school & $42(37.5)$ & $28(36.4)$ & $143(38.4)$ \\
\hline Higher education & $17(15.2)$ & $10(13)$ & $107(28.8)$ \\
\hline$P$ value & 0.78 & 0.083 & 0.001 \\
\hline \multicolumn{4}{|l|}{ Employment Status } \\
\hline Housewife & $91(80.5)$ & $64(83.1)$ & $239(64.2)$ \\
\hline Employed & $22(19.5)$ & $13(16.9)$ & $133(53.8)$ \\
\hline$P$ value & 0.695 & 0.393 & $<0.000$ \\
\hline \multicolumn{4}{|l|}{ Gravidity } \\
\hline $0-1$ & $25(30.9)$ & $29(37.7)$ & $60(18.8)$ \\
\hline $2-3$ & $55(58.7)$ & $38(49.4)$ & $254(68.3)$ \\
\hline$>4$ & $23(20.4)$ & $10(13)$ & $48(12.9)$ \\
\hline$P$ value & 0.557 & 0.075 & $<0.000$ \\
\hline \multicolumn{4}{|l|}{ Type of contraception } \\
\hline IUD & $12(12.2)$ & $5(7.4)$ & $48(13.4)$ \\
\hline Condon & $19(19.4)$ & $21(30.9)$ & $93(25.9)$ \\
\hline Withdrawal method & $34(34.7)$ & $15(22.1)$ & $146(40.7)$ \\
\hline$P$ value & 0.347 & 0 & 0.18 \\
\hline \multicolumn{4}{|l|}{ Spouse's educational level } \\
\hline illiterate & $11(9.9)$ & $2(2.6 \%)$ & $9(2.4 \%)$ \\
\hline Primary school & $25(22.4)$ & $25(32.5 \%)$ & $56(15.2 \%)$ \\
\hline Secondary school & $26(23.4)$ & $20(26 \%)$ & $73(19.8 \%)$ \\
\hline High school & $26(23.4 \%)$ & $16(20.8 \%)$ & $118(32.1 \%)$ \\
\hline University & $23(20.7 \%)$ & $14(18.2 \%)$ & $112(30.4 \%)$ \\
\hline $\mathrm{P}$ value & 0.968 & 0.459 & 0.001 \\
\hline
\end{tabular}

\section{Discussion}

According to results of this research, most of the women had low knowledge $(59.4 \%)$ about this test. A study in Brazil reported $46.1 \%$ of women interviewed showed adequate knowledge about the Pap test (Fernandes et al., 2009). On the other hand, only $13 \%$ of the participants in India were aware of Pap smears (Seth et al., 2005), and among Vietnamese households, less than twothirds $(62 \%)$ of the women knew that not receiving regular Pap tests increases the peril of cervical cancer (Do et al., 2007). Only $33 \%$ of women in Irbid, Jordan (Amarian et al., 2008), and $37 \%$ in Iran, Gonabad (Tabatabaee Kave et al., 2009) had enough knowledge.

According to results, $62.1 \%$ of individuals had weak practice related to Pap smears. The most common reason for not having a Pap smear test was lack of disease symptoms, lack of recommendations by physicians and the high cost of doing this test. Tabatabaee depicted that 52\% of persons had weak practice in Iran, Gonabad (Tabatabaee et al., 2009). In a Malaysian survey $25.3 \%$ had never had the Pap smear, and only $18.4 \%$ had their last examination within the last three years (Chee et al., 2003). Studies of Amarian and colleagues in Gordan showed approximately $95 \%$ of women had never done this screening test, also it was mentioned that the chief barriers of not referring were inadequate knowledge about this test, not receiving advice on performing this test by hygienic practitioners and fear of having a bad result (Amarian et al., 2008). Other reasons consisted of not having information about performing this test (Tung et al., 2010; Onsuz et al., 2014), lack of relationship between the health professionals and women (Awodele et al., 2011), high cost and fear of doing this test (Amarian et al., 2008), reluctance to go for medical tests due to the lack of any symptoms and apprehension to have a test that detects cancer (Basu et al., 2006; Tung et al., 2010; Ho et al., 2011).

In general, it seems that the most worldwide reasons 
Knowledge, Attitude and Practice about Pap Smear Test among Women Living in Bojnourd, North East of Iran for not doing this test were lack of proper knowledge about its necessity, the procedure of the Pap smear test and no practical relations between people and health professionals. However, in developing countries, knowledge about this cancer is limited and most women have not heard about cervix cancer and don't have any information about this screening test (Kidanto et al., 2002).

Most women ( $87.3 \%$ ) had a positive attitude about Pap smear tests. It is a principal reason that lack of knowledge among people is related to defects in hygienic policies and subsequently faults in informing system in Iran. Gamarra and colleagues also mentioned positive attitude in $80.5 \%$ of samples; it seems that protective and diagnostic features were important causes (Gamarra et al., 2005).

Findings described that there is a relationship between extent of knowledge, type of attitude and amount of practice, but there is not any relation between the type of attitude and practice. Other studies showed that knowledge of women about this cancer and the protection method had the strongest correlation with practice (Juon et al., 2003). The results of Awodele and colleagues revealed that 182 (91\%) of the respondents were aware of Pap smears; however, $159(79.5 \%)$ and $175(87.5 \%)$ of the respondents had never had a Pap smear (Awodele et al., 2011).

As results show, physicians and health protectors were the great source of gaining knowledge by women [47\%]. Physicians and health protectors in health care centers can play important roles by paying attention to necessity of doing this test (Chee et al., 2003). Other important sources include radio and television (Tabatabaee et al 2009), schools and public classes (Gregg et al., 2011).

Our results showed the absence of an association between enough knowledge and the variables. Also, all variables, except type of prevention method, did not associate with enough attitudes. However, relationships were found between enough knowledge with education, and enough attitude with education, job, parity and using of contraceptive methods (Gamarra et al., 2005) As about enough practice, we found an association with age, educational level, job, number of children, contraceptive method and husband's education. Some studies have shown a relationship between enough practice with being married, higher incomes, higher education, higher age and using the contraceptive pill or intra-uterine device (Chaudhry et al., 2003; Chee et al., 2003). Other studies have shown enough practice among women with lower income, lower parity and referring to health care unit On the other hand; a study reported that there was no association between practice and demographic characters (Do et al., 2007). The reason of less percentage of doing this test among older women in our study may have resulted from having enough children and likely their less referring to health centers for postnatal and family planning (Chee et al., 2003). Job, working outside home and upper education may be associated with not having enough time for referring to health center. Also, it may be the fault of informing programs in institutions and universities. In Iran, the middle class refer more to public health centers than the upper and working classes.

The difference between our findings and other research may be related to cultural differences, personal and ethnic to low awareness of women in Bojnourd and their low participation in screening programs of cervical cancer, the necessity of women's training in this case should have priority in hygienic policies of this province.

This study was a preliminary research to assay people's knowledge, practice and attitude about cervical cancer screening restricted to a special geographic area in northeastern Iran. Similar studies should be done in other areas of the country to generalize the findings. However, the findings of this research are very important for hygienic supervisors and policy makers who provide services for this group.

There are two limitations to this study. The participants 'answers probably tended to overestimate the frequency of tests and to underestimate the time of their last test.

\section{Acknowledgements}

The authors would like to express their heartiest appreciations to the women who participated in the study. Also we thank the instructors for their valuable contribution in data gathering and the researchers who evaluated validity of the questionnaire.

\section{References}

Akujobi CN, Ikechebelu JI, Onunkwo I, Onyiaorah IV (2008). Knowledge, attitude and practice of screening for cervical cancer among female students of a tertiary institution in South Eastern Nigeria. Niger J Clin Pract, 11, 216-9.

Amarian ZO, Badria LF, Obeidat BR (2008). Attitudes and beliefs about cervical smear testing in ever-married Jordanian women. Eastern Mediterranean Health J, 14, 389-97.

Anaya-Ruiz M, Vincent AK, Perez-Santos M (2014). Cervical cancer trends in Mexico: incidence, mortality and research output. Asian Pac J Cancer Prev, 15, 8689-92.

Awodele O, Adeyomoye AA, Awodele DF, et al (2011). A Study on Cervical Cancer Screening Amongst Nursesin Lagos University Teaching Hospital, Lagos, Nigeria. J Canc Educ, 26, 497-504.

Basu P, Sarkar S, Mukherjee S, et al (2006). Women's perceptions and social barriers determine compliance to cervical screening: Results from a population based study in India. Cancer Detect Prev, 30, 369-74.

Chaudhry S, Fink A, Gelberg L, Brook R (2003). Utilization of papanicolaue smear by south Asian women living in the united states. J Gen Intern Med, 18, 377-84.

Chee H, Rashidah S, Shamsuddin K, Intan O (2003). Factors related to the practice of breast self-examination (BSE) and Pap smear screening among Malaysian women workers in selected electronics factories. BMC Women's Health, 3, 3-10.

Do HH, Taylor VM, Burke N, et al (2007). Knowledge about cervical cancer risk factors, traditional health beliefs, and Pap testing among Vietnamese American women. J Immigr Minor Health, 9, 109-14.

Fernandes JV, Rodrigues SH, Costa YG, et al (2009). Knowledge, attitudes, and practices related to Pap test by women, Northeastern Mexico. Rev Saude Publica, 43, 851-8.

Gakidou E, Nordhagen S, Obermeyer Z (2008). Coverage of cervical cancer screening in 57 countries: low average levels and large inequalities. PLoS Med, 5, 132.

Gamarra CJ, Paz EP, Griep RH (2005). Knowledge, attitude and 
Maryam Bolandhemmat et al practice related to papaniculaou smear test among argentines' women. Rev saude publica, 39, 270-6.

Gichangi P, Estamble B, Bwayo J (2003). Knowledge and practice about cervical cancer and pap smear testing among patients at kenyatta national hospital, Nairobi,Kenya. Int $J$ Gynecol Cancer, 13, 827-33.

Gregg J, CenturionT, Aguillon R, et al (2011). Beliefs about the pap smear among Mexican immigrants. J Immigr Minor Health, 13, 899-905.

Ho IK, DinhKT (2011). Cervical Cancer Screening Among Southeast Asian American Women. J Immigr Minor Health, 13, 49-60.

Ilter E, Celik A, Haliloglu B, et al (2010). Women's knowledge of Pap smear test and human papillomavirus: acceptance of HPV vaccination to themselves and their daughters in an Islamic society. Int J Gynecol Cancer, 20, 1058-62.

Juon HS, Seung-Lee C, Klassen AC (2003). Predictors of regular Pap smears among Korean-American women. Prev Med, 37, 585-592.

Khan HM, Gabbidon K, Abdool-Ghany F, et al (2014). Health disparities between Black Hispanic and Black Non- Hispanic Cervical Cancer Cases in the USA. Asian Pac J Cancer Prev, 15, 9719-23.

Kidanto HL, Kilewo CD, Moshiro C (2002). Cancer of the cervix: knowledge and attitudes of female patients admitted at Muhimbili National Hospital, Dar es Salaam. East Afr Med journal, 79, 467-75.

Monsonego J (2007). Prevention of cervical cancer: screening, progress and perspectives. Press Med, 36, 92-111.

Onsuz MF, Hidiroglu S, Sarioz A, et al (2014). Knowledge, attitudes and behaviors of women over 20 years old on cervix cancer in Istanbul, Turkey. Asian Pac J Cancer Prev, 15, 8801-7.

Othman NH, Mohamad Zaki FH (2014). Self-collection tools for routine cervical cancer screening: a review. Asian Pac J Cancer Prev, 15, 8563-9.

Ranabhat S, Tiwari M, Dhungana G, Shrestha R (2014). Association of knowledge, attitude and demographic variables with cervical Pap smear practice in Nepal. Asian Pac J Cancer Prev, 15, 8905-10.

Serrano-Olvera A, Cetina L, Coronel J, Duenas-Gonzalez A (2014). Follow-up consultations for cervical cancer patients in a Mexican cancer center. Comparison with NCCN guidelines. Asian Pac J Cancer Prev, 15, 8749-52.

Seth T, Kotwal A, Thakur R, et al (2005). Common cancers in India: knowledge, attitudesandbehaviours of urban slum dwellers in New Delhi. Public Health, 119, 87-96.

Tabatabaee Kave M (2009). Surveying of knowledge, attitude and practice of staffs in health centrals of Iran - Gonabad about papsmear and cervical cancer screening. J Gonabad University, 12, 47-54.

Tung WC, Lu M, Cook D (2010). Papanicolaou screening in Taiwan: perceived barriers and self-efficacy. Health Care Women Int, 31, 421-34.

WHO (2013). WHO fact sheet: Human papillomavirus (HPV) and cervical cancer. Retrieved from http://www.who.int/ mediacentre/factsheets/fs380/en/, August 2014.

Wright KO, Kuyinu YA, Faduyile FA (2010). Community education on cervical cancer amongst market women in an urban area of Lagos, Nigeria. Asian Pac J Cancer Prev, $11,137-40$. 